\title{
Economies of density for on-site waste water treatment
}

\author{
Eggimann Sven ${ }^{1,2}$, Truffer Bernhard ${ }^{1,3}$, Maurer Max $^{1,2}$ \\ 1 Eawag, Swiss Federal Institute of Aquatic Science and Technology, 8600 Dübendorf, Switzerland. \\ 2 Institute of Civil, Environmental and Geomatic Engineering, ETH Zürich, 8093 Zurich, Switzerland. \\ 3 Faculty of Geosciences, Utrecht University, Heidelberglaan 2, NL-3584 CS Utrecht, The Netherlands.
}

\section{Keywords}

on-site treatment costs

sewage sludge logistics

degree of centralization

network externality

economies of scale

decentralized wastewater infrastructure

\begin{abstract}
Decentralised wastewater treatment is increasingly gaining interest as a means of responding to sustainability challenges. Cost comparisons are a crucial element of any sustainability assessment. While the cost characteristics of centralised waste water treatment (WMS) have been studied extensively, the economics of decentralised WMS are less understood. A key motivation for studying the costs of decentralised WMS is to compare the cost of centralised and decentralised WMS in order to decide on cost-efficient sanitation solutions. This paper outlines a model designed to assess those costs which depend on the spatial density of decentralised wastewater treatment plants in a region. Density-related costs are mostly linked to operation and maintenance activities which depend on transportation, like sludge removal or the visits of professionals to the plants for control, servicing or repairs. We first specify a modelled cost-density relationship for a region in a geometric two-dimensional space by means of heuristic routing algorithms that consider time and load-capacity restrictions. The generic model is then applied to a Swiss case study for which we specify a broad range of modelling parameters. As a result, we identify a 'hockey-stick'-shaped cost curve that is characterised by strong cost reductions at high density values which level out at around 1 to 1.5 plants per $\mathrm{km}^{2}$. Variations in the cost curves are mostly due to differences in management approaches (scheduled or unscheduled emptying). In addition to the well-known diseconomies of scale in the case of centralised sanitation, we find a similar generic cost behaviour for decentralised sanitation due to economies of density. Low densities in sparsely populated regions thus result in higher costs for both centralised and decentralised system. Policy implications are that efforts to introduce decentralised options in a region should consider the low-density/highcost problem when comparing centralised and decentralised options.
\end{abstract}




\section{Introduction}

\subsection{Comparing central and decentral sanitation costs}

$C$ osts are an integral criterion for decisions on suitable wastewater man-

$\checkmark$ agement systems (WMS) for both centralised and decentralised scenarios (inter alia Hamilton et al. 2004, Maurer et al. 2006, Libralato et al. 2012, Truffer et al. 2013). Decentralised WMS are increasingly considered as potential substitutes for centralised WMS with sewer networks (inter alia Tchobanoglous et al. 2004, Massoud et al. 2009, Larsen et al. 2013, OECD 2015). Typically, decentralised WMS - also called on-site (OST) treat small wastewater flows in individual residences or residential clusters (cf. Tchobanoglous and Leverenz 2013), which can, as a consequence, save on extensive sewer networks (Libralato et al. 2012). However, it is a complex task to determine the optimal degree of centralisation in water and wastewater management (Eggimann et al. 2015, Poustie et al. 2014, Adams et al. 1972, 'Guo and Englehardt 2015, Lee et al. 2013) because the overall costs in a region depend not only on the sum of the costs of all individual technological components but also on how they are spatially distributed. This implies that besides the usual cost-driving factors like context uncertainties, economies of scope, economies of scale or high network infrastructure life-spans (Hansman et al. 2006, 'Markard 2009', 'Starkl et al. 2012), space-dependent cost items such as economies of density and network externalities have to be taken into account.

In the case of centralised WMS, space-dependent cost effects play out in the form of major economies of scale at the level of the wastewater treatment plant (i.e. per capita costs decrease with the number of people in a catchment connected to it), whereas the costs of building up a sewer system show diseconomies of scale (i.e. to reach full connection more distant settlements need to be connected). These cost characteristics have been intensively discussed in the literature (cf. Townend 1959, Downing 1969, Adams et al. 1972, Haug 2004, Friedler and Pisanty 2006, Maurer et al. 2006/2010). Nevertheless, the cost characteristics of OST systems are much less well known. In general, unit prices of OST plants do not depend on the number of units installed in a specific region. However, management, maintenance and regulation schemes may turn out to be very costly, because travel costs for service teams may become important (inter alia Kennedy-Walker et al. 2014, Semiyaga et al. 2015, Hamilton et al. 2004, Kaminsky and Javernick-Will 2013). An integrated assessment of these different cost components for determining the optimal degree of centralisation in a region is however lacking (Hamilton et al. 2004, OECD) 2015, Eggimann et al. 2015). The optimal degree of centralisation is directly linked to the OST plant density, as this increases in response to growing population percentages serviced by on-site treatment plants. In this 
paper we examine an essential parts of such an integrated cost assessment, which are arguably the least well understood, namely those that are related to spatial density of OST plants. We present a model-based approach to examining the economies of density ${ }^{1}$ of OST plants and conduct a sensitivity analysis of different management approaches. A model-based approach is needed because cost-data collection is challenging and there is a lack of available data to carry out a systematic comparison of the costs of different WMS in a region.

\subsection{How space and transportation influence costs}

$\mathrm{T}$ the field of spatial economics, the important influence of spatial dis1 persion on service provision has long been postulated (Wegener 2011): many different theoretical models based on transportation-cost considerations have been developed, such as 'von Thünen's (1875)! ring model, 'Christallers' (1933) model of optimal provision or the optimal city-size model of 'Arnott (1979). Such studies highlight the fact that the transportation of material or personnel are critical for efficient service provision. Much research has consequently evolved around space-dependent cost efficiencies in many different infrastructure fields ${ }^{2}$ ), including the water and wastewater sector (cf. 'Guerrini et al. 2013, 'Álvarez et al. 2014). The finding that the operation and maintenance (O\&M) costs of point-type infrastructures are particularly dependent on the settlement or population density is especially interesting with respect to OST systems (inter alia Schiller and Siedentop 2005, Wenban-Smith 2009). As a consequence, we expect the haulage distance to be crucial for assessing the O\&M costs of OST systems (Semiyaga et al. 2015). Despite this long-known influence, the spatial cost effects concerning the O\&M of OST plants have not been systematically estimated. Furthermore, the literature often focuses on single cost aspects of decentralised wastewater O\&M such as monitoring (inter alia Hug and Maurer 2012) or sludge transportation (inter alia Steiner et al.: 2002). Nevertheless, there are some notable exceptions explicitly focusing on the road-based transportation needed in the case of OST plants: Steiner et al. (2002) propose a simple method for estimating the haulage costs on the basis of geometrical and economic criteria, and have used it to find decreasing costs with higher population densities. Flotats et al.

\footnotetext{
'González-Gómez and García-Rubio (2008)' differentiate between economies of product density and economies of customer density. The former denotes the marginal cost savings of a fixed number of consumers due to increased consumption. The latter refers to the cost savings achieved by the higher efficiency resulting from a larger number of consumers. We focus on economies of customer density, implying that the marginal costs of providing services decrease with an increasing number of customers in a spatially defined area. We refer to 'Holmes (2011)' for an overview of the literature focusing on economies of density in other thematic fields.
}

Typically, examples can be found in solid waste management (inter alia Zamorano et al. 2009, Tavares et al. 2009, 'Ghose et al. 2006). See Section 4.3 for further applications. 
(2009) show that minimising transportation costs is vital for manure management, a factor that is highly relevant to wastewater transportation in OST plants. The authors compare on-farm and centralised treatments and conclude that transportation costs are crucial for deciding between centralised and decentralised strategies. 'Marufuzzaman et al. (2015)' present a method to compare pipeline and truck-based transportation of wastewater sludge and perform a cost analysis based on transported volumes and distances. Whereas different treatment options might result in different operating and maintenance requirements, Etnier et al. (2000) note that cost differences can be expected to result from the different strategies of collecting and maintaining WMS.

We believe the paucity of literature about O\&M for OST systems to be responsible for rather speculative and vague overall cost claims (Hamilton et al. 2004, Dodane et al. 2012, 'Singh et al. 2015, Hendrickson et al. 2015, Truffer et al. 2013, Etnier et al. 2000). As a result, many authors conceive O\&M of OST systems as costly, which adds to the conventional wisdom that decentralised WMS are challenging to operate and manage (inter alia Bakir 2001, Parkinson and Tayler 2003, Maurer et al. 2006, Buchanan et al. 2014). The methodological framework introduced in this paper enables the systematic assessment of cost effects relating to OST plant density by examining the most important space-related costs (residual transportation, service and repair costs), and in doing so prepares the ground for an integrated assessment of the optimal degree of centralisation in the provision of regional wastewater infrastructure. It is not the aim of this paper to perform a comprehensive overall cost analysis.

\section{Materials and methods}

We first identify those cost items which depend on the spatial densi-

ty of plants in a region and differentiate between two management approaches for sludge emptying at OST plants. We then give a general methodological overview and explain the routing algorithms in detail. Section 2.5 presents the distance parameter estimation, followed by information on cost parameters and a sensitivity analysis. Section 2.8 introduces the case study.

\subsection{Tasks sensitive to economies of density}

W e do not intend to perform a full cost comparison of OST systems or a complete analysis of O\&M costs, but only aim to identify space-related costs. Therefore we do not consider investment or capital costs or all fixed costs, and particularly not costs independent of space. By the same logic, we also treat variable costs which depend on the chosen OST system or specific external conditions being constant, such as sludge treatment, 
energy consumption, chemical acquisition or other expenses such as taxes (see i.e. Fletcher et al. 2007, WERF 2015). Such costs can simply be added as fixed baselines to the costs calculated in this paper, depending on the chosen technological solution. Further items such as regulatory costs may also be included in this broad conceptualisation. However, we maintain that these items follow the same logic and could therefore be easily added to an overall cost assessment.

We consider three typical tasks that exhibit cost characteristics which are space-dependent; namely, i.) residual (sludge and scum) emptying, ii.) service and iii.) repairs, as detailed below. Specific task execution may differ depending on the technical details of the chosen OST plant. As we outline below for each specific task, depending on the decentralised WMS, less service and repairs may be needed or the amount of sludge and scum may differ ${ }^{3}$ (we exemplarily refer to Singh et al. (2015) and 'Crites and Tchobanoglous (1998)' for various technology options). We assume that these tasks are carried out by specialised external contractors (operator model) who have to travel to the treatment plants, as proposed for example by Massoud et al. (2009)!

- i.) Residual emptying: Wastewater treatment produces sludge and scum which needs to be disposed of within certain time intervals. We assume that this disposal is performed by a specialised contractor. The accumulated volume per population equivalent (PE) depends on the given technical system and the sludge residence time. The haulage of these residuals is context-dependent (Mikhael et al. 2014) but is commonly road-based and is typically carried out by a suction truck with a specific load capacity and an average travelling speed for collection. The process of emptying is time-consuming, as the treatment plants need to be accessed, the sludge pumped, and further tasks such as filling out paperwork completed.

- ii.) Service: The long-term reliability of OST systems depends on maintenance and reporting (Bradley et al. 2002). In order to perform maintenance work (such as membrane regeneration or similar) or simply to check functionality, OST systems typically need to be visited by a competent service contractor. How often this has to

3 The same is true for the amount of time needed for system maintenance, which might differ considerably (e.g. the maintenance time of a reed-bed treatment plant system differs from that of a sequencing batch reactor). However, these three tasks must be performed in some way, irrespectively of the choice of OST system. For this paper, the chosen parameter values apply especially to membrane bio-reactors (MBR) or sequencing batch reactors (SBR). However, the previously outlined operationalisation of space-dependent costs can be specifically adapted to other systems such as septic tanks or reed-bed based systems. 
be done depends on the complexity of the OST system, the sensor technology equipment and the required level of monitoring (ibid.). Depending on the management model, legal situation and treatment system, the number of visits or the type of tasks to be performed differ. We make the simplifying assumption that the service task is independent of the residual emptying and performed within certain time intervals by a mobile technician spending an average amount of service time per OST system plus travelling time.

- iii.) Repairs: If an OST system fails, a technician needs to visit the plant and perform specific repairs. We assume that enough funds are available for these repairs and that failing systems require mandatory repair. How often the system fails depends on its type and the quality of its service and control. In reliability engineering, the frequency of failure is commonly expressed as a failure rate (Finkelstein 2008). We consider the repair tasks to be similar to service tasks by assuming that a technician has to visit the plant in a vehicle and needs an average repair time to do the job. Given the scope of this paper, we do not relate service frequency with failure rates.

\subsection{Differentiating management approaches}

7 fficiency and cost-effectiveness are major goals of logistics management. Therefore it is important to consider different management approaches in order to assess their impact. In this section, we present two ideal types of management for residual emptying which represent a worst (unscheduled) and best-case (scheduled) emptying approach.

- Scheduled: For scheduled emptying, we assume that the plants are evacuated periodically and an optimal routing plan can be set up. We make the simplifying assumption that all OST plants are full at the time of emptying. This assumption allows each OST plant to be visited along an optimal collection tour and the truck's storage capacity to be exploited to the maximum at all times. We consider this emptying approach to be the most efficient one from a logistics point of view, yielding the best theoretical solution.

- Unscheduled: For unscheduled emptying, the collection tour is determined on the basis of whether the OST plant emptying is needed due to critical tank filling. We assume that the plant owners will call the operator (or the plant will send a signal) when the tank capacity limits are reached. This results in different daily collection tours depending on the number of people calling and their geographical position. 
In real world situations, tank filling rates will in general not be constant. As a consequence, some tanks will have to be evacuated earlier than expected or would not be full at the time of emptying. Differences in filling rates may be due to variations in the number of users per plant, particularly over time. Examples with highly varying rates would include tourist regions with many part-time residences. The two ideal approaches of scheduled and unscheduled emptying therefore represent best and worst-case scenarios. More realistic situations can be considered as lying somewhere between these two extremes.

\subsection{Modelling setup}

$T$ he proposed modelling procedure derives a cost-curve for different 1 treatment plant densities. The basic idea is to assess the costs of the tasks outlined in Section 2.1 for a specific number of OST plants with a given treatment volume. For modelling purposes, we identify density values by calculating the space-dependent costs for a sequence of circular catchment areas. Different densities result from an incremental decrease of the catchment area diameter (see Figure 1). ${ }^{4}$ For each catchment, we randomly

4 A more intuitive operationalization of densities would have been to increase the number of OST plants in a given region. Instead we chose a fixed number of OST plants in a decreasing set of smaller areas. The main reason for this is that we wanted to correct for influences of specific geographical clustering, while still being able to run meaningful

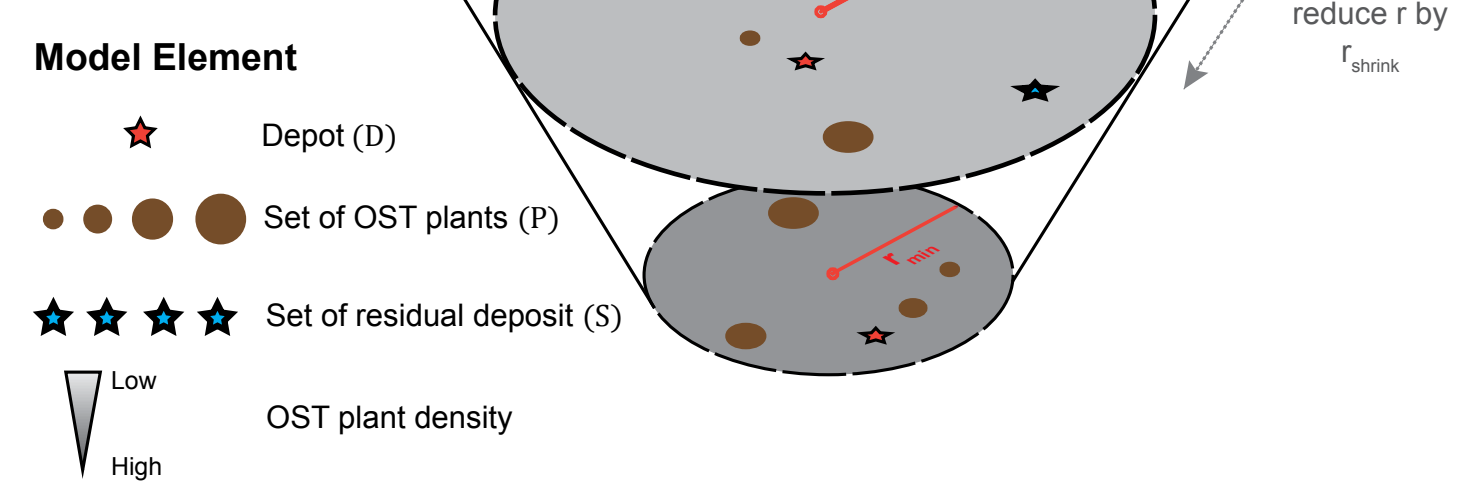

Figure 1: Visualisation of the schematic modelling approach. 
distribute a fixed number $\mathrm{n}$ of OST plants, and a relative number $\mathrm{m}$ of residual deposits (places where the sludge can be discharged). ${ }^{5}$ Additionally, one depot (the operating basis for the emptying vehicle and its driver) is positioned near the most central residual deposit. The following cost calculation steps are executed for each catchment area (cf. Figure 2 for more

routing procedures. Holding the number of OST plants constant has the advantage that different density values remain largely comparable. Geographical variations will be taken into consideration by the values of parameter $\mathrm{f}_{\mathrm{d}}$.

5 We assume that the sludge can be treated at large conventional treatment plants, which allows us to easily calculate $\rho_{\text {deposit }}$ based on the number of today's existing plants of this kind. Depending on the specific application case, the rationale for defining the deposit density may be different (for example whether we assume that additional special sludge treatment units are constructed or that all residuals are transported to existing treatment plants).

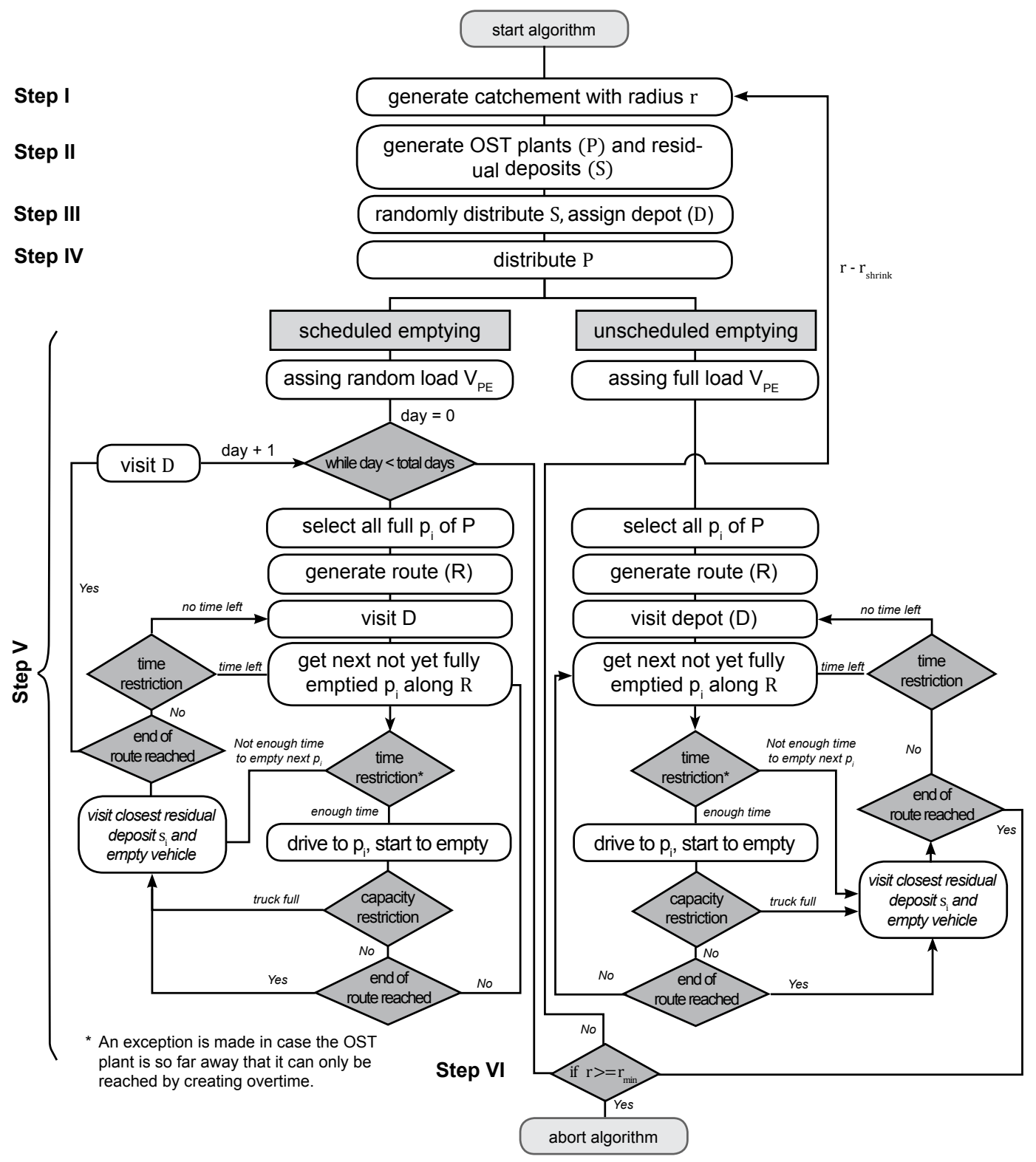

Figure 2: ULM diagram of the methodological approach. 
details and Table 1 for an overview of all model parameters):

Step I: In each iteration step, the catchment area of the system is defined as a circle of radius $r$, which we denote in the first iteration as rinitial. We define the initial radius as the maximum distance a vehicle can reach within one working day (Eq.1):

$$
r_{\text {initial }}=\frac{v_{\text {truck }} * t_{\text {drive }}}{2}
$$

where: $\mathrm{v}_{\text {truck }}=$ average vehicle speed and $\mathrm{t}_{\text {drive }}=$ maximum possible driving time per day. The rationale for choosing this maximum radius is that even the most distant OST plants can be reached from the depot within one working day. ${ }^{6}$

Step II: We generate a set of OST plants $\mathrm{P}=\left\{\mathrm{p}_{1}, \mathrm{p}_{2}, \ldots, \mathrm{p}_{\mathrm{n}}\right\}$ consisting of a fixed number (n) of individual plants $\left(\mathrm{p}_{\mathrm{i}}\right)$. To each of these individual plants we attribute a load (within a given range) given in population equivalents $\mathrm{V}_{\mathrm{i}}^{\mathrm{PE}}$. On the basis of this load $\mathrm{V}_{\mathrm{i}}^{\mathrm{PE}}$ and the sludge accumulation rate $\left(\mathrm{r}_{\text {acc }}\right)$, we then calculate the total sludge and scum accumulation for all $\mathrm{p}_{\mathrm{i}}$. In the case of scheduled emptying we attribute the maximum possible load $\mathrm{V}_{\mathrm{i}}^{\mathrm{PE}}$ to each plant. In the unscheduled mode, $\mathrm{V}_{\mathrm{i}}^{\mathrm{PE}}$ are set at a random level.

Additionally, we create a set $S=\left\{\mathrm{s}_{1}, \mathrm{~s}_{2}, \ldots, \mathrm{s}_{\mathrm{m}}\right\}$ of individual residual deposits $\left(\mathrm{s}_{\mathrm{j}}\right)$. The number of deposits $\mathrm{m}$ is calculated on the basis of the

6 Because of distance weighting, travelling times might be longer than the daily working time. Including the time needed to empty the sludge at the disposal point might therefore result in daily overtime. 


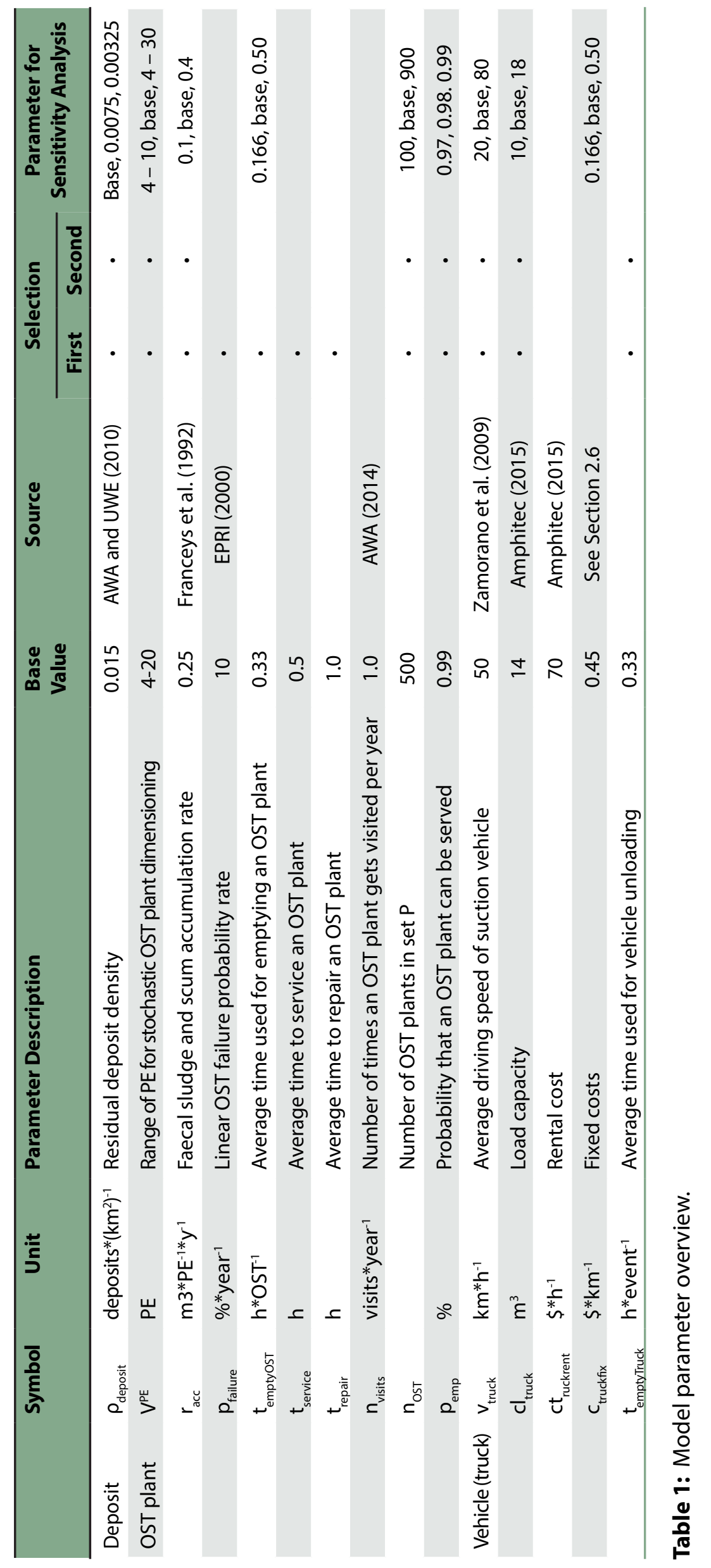




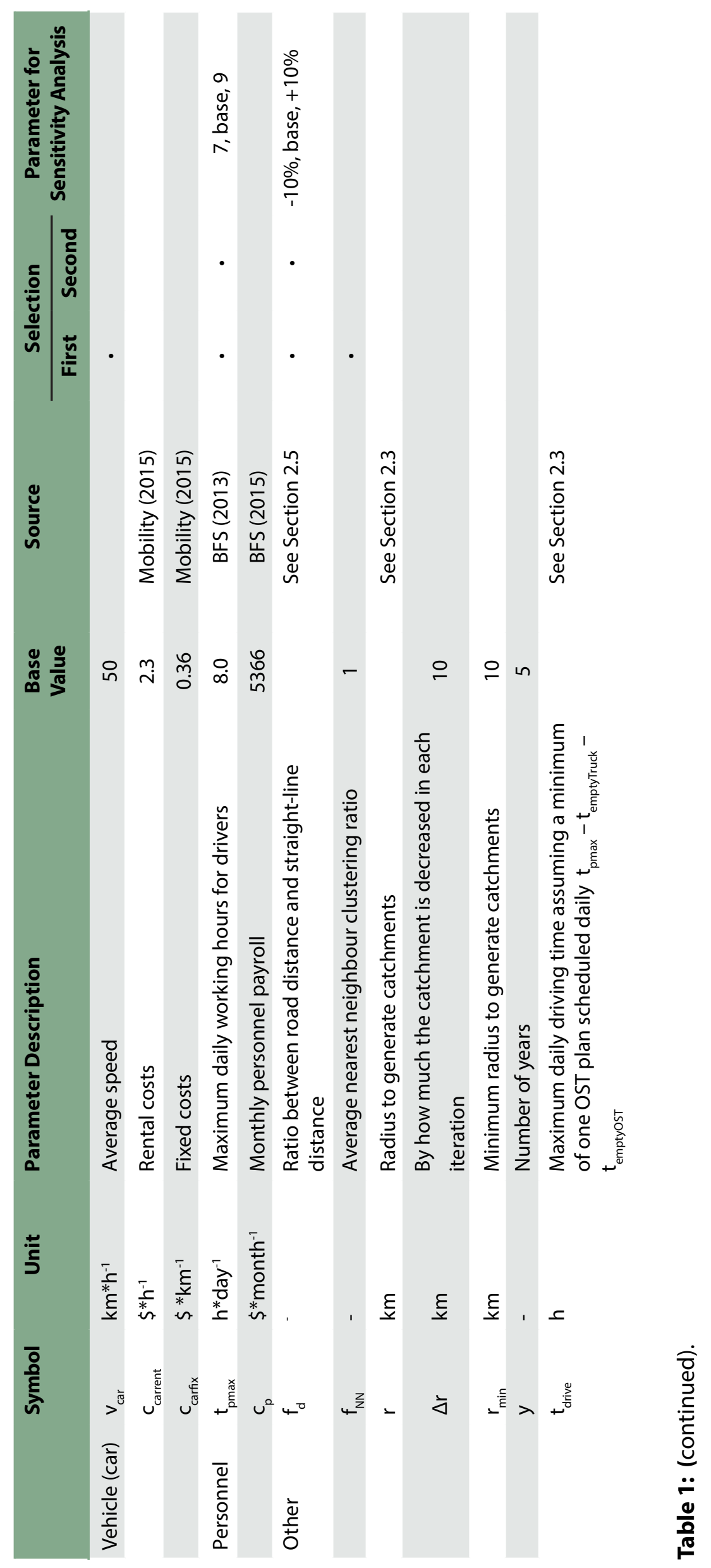


deposit density factor $\left(\rho_{\text {deposit }}\right)$ for each radius. This way we assume that the total number of deposits in a region is set largely constant despite a density increase.

Step III: We randomly distribute all sj within the catchment area and assign a single depot to the $\mathrm{s}_{\mathrm{j}}$ closest to the centre of this area.

Step IV: We randomly rearrange all pi until we reach a Nearest Neighbour Index (Clarke et al. 1964) of $\mathrm{f}_{\mathrm{NN}}=1$ in order to ensure the same degree of clustering for all $r$. This allows a like-for-like comparison, independent of the catchment radii, and ensures that the cost differences found do not result from different degrees of clustering. An alternative to a random distribution of OST plants within the catchments would be a selection of possible OST plant sites with the aid of real settlement structures. However, the formulation of detailed (spatial) technological transition models is complex (cf. Zeppini et al. 2014) and not appropriate given the generality of the modelling approach.

Step V: We calculate the costs for a contractor travelling to the plant by means of a routing algorithm (described in Section 2.4). This provides us with a point estimate for the respective density measure.

Step VI: We decrease the catchment radius $r$ by $\Delta r$, keeping $r \geq r_{\text {min }}$ and loop back to Step II. $\Delta \mathrm{r}$ and $\mathrm{r}_{\text {min }}$ are technical parameters for determining the number of iterations in the algorithm. Choosing smaller values for $\Delta r$ simply increases the number of iterations, while $r_{\min }$ denotes the maximum density beyond which we no longer observe any significant cost reductions.

\subsection{Routing algorithms}

Tn this section, we explain our cost calculations for the logistics of OST 1 plant O\&M services in detail for the case of residual emptying (cf. Figure 2 , Step V). We apply different routing algorithms depending on the chosen management approach (Section 2.3). A schematic example of scheduled and unscheduled emptying approaches is visualised in Figure 3.

We generate collection tours for both emptying modes with the aid of route optimisation techniques. We use algorithms based on heuristic routing (Cormen et al. 2009) with the aim of finding a minimum path between a given set of destinations. This is commonly referred to as the Vehicle Routing Problem, which adds capacity constraints to the common Travelling Salesman Problem (Lawler et al. 1985). We refer to 'Gendreau' et al. (1996) for an overview of the numerous approaches to addressing the Vehicle Routing Problem. We use heuristics in order to avoid a 
heavy computational burden and choose the classical Nearest Neighbour Algorithm because of its intuitiveness (Johnson and Papadimitriou 1985). Heuristically determined solutions rarely constitute an optimum: however, they give good approximations in many applications with a reasonable computational burden (Michaelewicz and Fogel 2004). For validation purposes, we compare the applied Nearest Neighbour algorithm with a computationally more expensive algorithm developed by 'Clarke and Wright (1964).

The various tasks such as emptying an OST plant $\left(\mathrm{t}_{\text {emptyosT }}\right)$, travelling to the depot or to an OST plant and emptying a suction truck $\left(\mathrm{t}_{\text {emptyTruck }}\right)$ require a time t. We determine the required travel time on the basis of the distances travelled and average travelling speed $\left(\mathrm{v}_{\text {truck }}\right)$ and choose reasonable value ranges for the remaining time parameters. We then use cost parameters $\left(c_{\mathrm{p}}, c_{\text {truckrent }}, c_{\text {truckix }}\right.$ ) to convert the time taken or distances travelled into total costs.

The routing algorithms for the different tasks are based on the following logic:

- Scheduled emptying tour: We assume that the collector can set up an optimal route for the entire catchment, so all OST plants are considered for optimal tour calculations and are always filled to a maximum $V_{i}^{\mathrm{PE}}$ (compare Figure 2). The tour starts at the depot and continues along the optimal route until all OST plants are emptied. ${ }^{7}$ For the case of residual emptying, we consider two restrictions which influence the theoretical optimal route, namely the maximum vehicle load capacity $\left(\mathrm{cl}_{\text {truck }}\right.$ ) and the maximum number of working hours per day $\left(\mathrm{t}_{\mathrm{pmax}}\right)$.These restrictions primarily influence the degree to which the suction truck deviates from its optimal route. For every OST plant visit, only as much sludge is emptied as fits the free capacity of the suction truck. If the maximum load is reached, the truck visits the closest residual deposit in order to dispose of its load. If some daily working time is left to continue the tour, the truck resumes its emptying work, otherwise it returns to the depot for the night. If the time restriction is reached even though the truck is not completely filled, it first visits the closest residual deposit and then returns to the depot in order to start a new working day. Cost calculations for scheduled emptying are based on a single tour where all OST plants are visited only once (see Figure 2).

7 We do not differentiate between the directions of the tour and randomly decide between a clockwise or anticlockwise direction starting from the depot. 


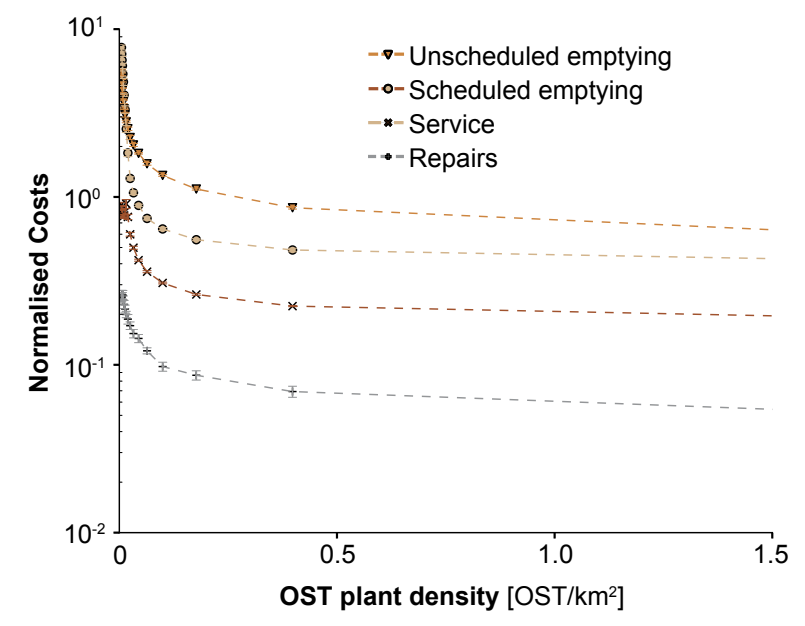

Figure 4: Normalised costs $(1=\$ 6.2 \mathrm{PE}-1 \mathrm{yr}-1)$ for the scheduled and unscheduled emptying approaches, and for the service and repair tasks (base parameters, $\mathrm{n}=10$ ). The error bars show the uncertainty resulting from different OST plant placement in the catchments.

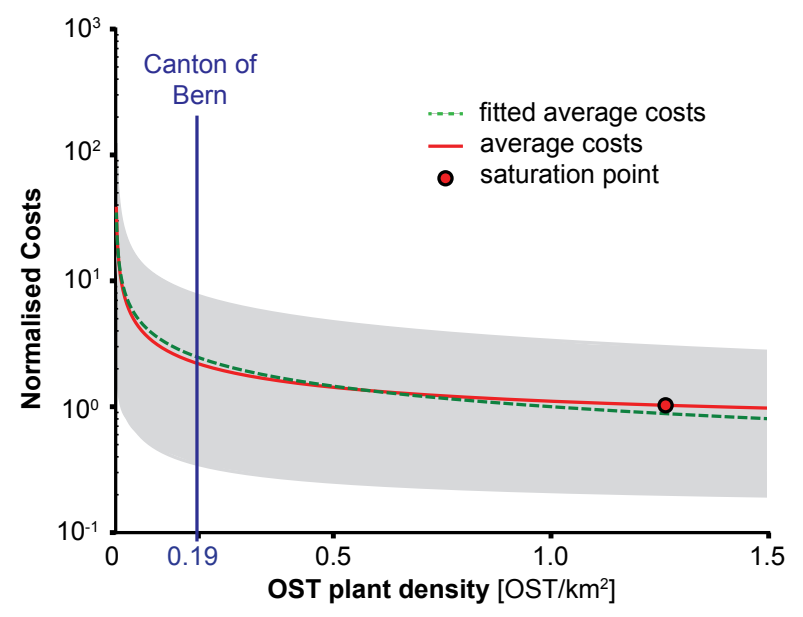

Figure 5: The average normalised cost $(\mathrm{NC})$ curve $\left(1=\$ 5.6 \mathrm{PE}^{-1} \mathrm{yr}^{-1}\right)$ is indicated in red: it can be approximated with $N C=x^{-0.90}(n=100)$. The grey area shows the result range. Today's average OST plant density for the whole case study area is indicated with the blue line.

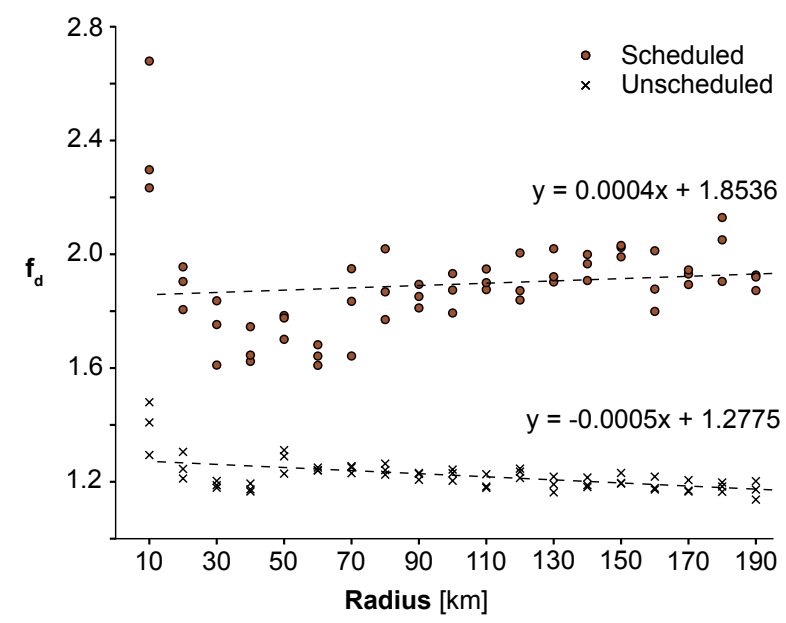

Figure 6: Distance factor estimation for the scheduled and unscheduled emptying approach. 
- We further assume that within a certain probability $\left(\mathrm{p}_{\text {emp) }}\right.$ an OST plant may be not emptied due to unexpected events (such as the absence of the house owner making the property inaccessible). This results in distances travelled and time spent without task accomplishment and leads to tour deviations, since OST plants need to be visited again in a later tour.

- Unscheduled emptying tour: In the case of unscheduled emptying we initially assign a random tank filling level to each OST plant. Then we increase the level iteratively by a constant daily sludge and sum accumulation rate $\left(r_{\text {acc }}\right)$ over a number of years (y). Finally, we calculate collection tours for each day based on the OST plants filled on each respective day. The procedure of collection and transport for the individual daily tours is analogous to the scheduled tour calculation. However, itis repeated for unscheduled emptying over several years (y) in order to calculate average costs. ${ }^{8}$

- Service tour: The algorithm for the service tour is very similar to that for scheduled emptying. The sole methodological difference is that we only consider the restriction on maximum working hours and use different values for the corresponding parameters $\left(\mathrm{v}_{\text {car }}, \mathrm{c}_{\mathrm{ca}-}\right.$ rrent, $, \mathrm{c}_{\text {carfix }}, \mathrm{n}_{\text {visits }}, \mathrm{t}_{\text {service }}$.

- Repair tour: The repair task tour calculation is similar to that for unscheduled emptying. We set up the tours daily only on the basis of the failed OST plants. In order to calculate the average repair costs per year, we also perform an iteration over a number of years (y). As only limited knowledge is available about the failure rates of OST plants, we use linear failure rates $\left(\mathrm{p}_{\text {failure }}\right)$ taken from the literature (EPRI 2000). The only restriction on the repair task is the maximum number of working hours per day for the tour generation. Corresponding time and cost parameters are also used $\left(\mathrm{t}_{\text {repair }}\right)$.

\subsection{Distance factor estimation}

$T$ he model distance calculations are based on straight-line distances.

1 In order to derive more realistic distances, we introduce a weighting factor $\left(f_{d}\right)$. This $f_{d}$ enables the model to be adapted to different geographies where distance calculations differ because of topographical characteristics

8 Most management approaches probably lie somewhere between the scheduled and unscheduled emptying tours, as we often find intermediate approaches where for example certain geographical regions are scheduled to be served within a certain time window and OST plant owners need to call if they want to have their OST serviced or emptied within this time frame. Furthermore, due to discontinuous OST plant filling rates, it may not be feasible to set up a purely scheduled approach. 
and the existing road network (e.g. objects like lakes or mountains which require detours). We use different weighting factors for scheduled and unscheduled emptying and estimate the distance factor for different distance radii. For the case study (see Section 2.8 ) we estimate $f_{d}$ for scheduled and unscheduled emptying with the aid of the Dijkstra (1959), algorithm by comparing the road-based and straight-line distances for all calculations on the basis of the actual road network (Figures 6 and A.1).

\subsection{Cost parameters}

$T$ he estimation of transportation costs is central for the proposed mod1 elling approach. Fuel consumption, wear, repairs, insurances, payload, truckload, routine maintenance and depreciation are typically considered in estimating transportation costs (inter alia Barnes and Langworthy 2003, Cambridge Systematics 1995). For this study, we calculate fixed transportation costs per km by assuming constant fuel consumption independently of the load $\left(c_{\text {truckix }}\right)$. We further assume that our vehicles are rented in order not to incorporate idle capacities in our study. This means that all costs relating to maintenance, repair or insurance of the vehicle etc. are included in the rental costs $\left(\mathrm{c}_{\text {truckrent }}\right)$. All costs are given per capita and year and we convert local currencies to US\$ using purchase power parities for the year 2013 (World Bank 2014).

\begin{tabular}{|c|c|c|c|c|c|c|}
\hline \multicolumn{4}{|c|}{ Scheduled Emptying } & \multicolumn{3}{|c|}{ Unscheduled Emptying } \\
\hline$r$ & $\begin{array}{c}\text { CW } \\
\text { [\$/PE/year] }\end{array}$ & $\begin{array}{c}\text { NN } \\
{[\$ / P E / y e a r]}\end{array}$ & {$[\%]$} & $\begin{array}{c}\mathrm{CW} \\
{[\$ / \mathrm{PE} / \text { year }]}\end{array}$ & $\begin{array}{c}\text { NN } \\
{[\$ / P E / y e a r]}\end{array}$ & {$[\%]$} \\
\hline 10 & 3.3 & 3.3 & 0 & 4.9 & 4.8 & 1 \\
\hline 20 & 3.9 & 3.7 & 4.3 & 6.9 & 6.7 & 3.4 \\
\hline 30 & 4.4 & 4.3 & 3 & 8.8 & 8.6 & 1.5 \\
\hline 40 & 5 & 5 & 0.8 & 11 & 10.4 & 1.4 \\
\hline 50 & 5.9 & 5.8 & 1.4 & 12.4 & 12.2 & 1.6 \\
\hline 60 & 7 & 6.9 & 1.7 & 14.2 & 14.1 & 0.8 \\
\hline 70 & 8.37 & 8.2 & 2 & 16 & 15.8 & 0.7 \\
\hline 80 & 10.4 & 10 & 3.6 & 18.2 & 17.5 & 3.8 \\
\hline 90 & 14.7 & 14.2 & 3.2 & 20 & 19.7 & 1.2 \\
\hline 100 & 20.5 & 19.7 & 4.2 & 22.2 & 21.7 & 2.2 \\
\hline 110 & 27 & 25.7 & 5 & 24.2 & 23.9 & 1.3 \\
\hline 120 & 32.9 & 31.3 & 5.2 & 26.4 & 26 & 1.7 \\
\hline 130 & 37.5 & 37.5 & 0 & 28.2 & 28.5 & -1.1 \\
\hline 140 & 43 & 41.9 & 2.6 & 31 & 30.6 & 1 \\
\hline 150 & 48.6 & 46.8 & 3.8 & 34.2 & 33.4 & 2.1 \\
\hline 160 & 52.9 & 50.6 & 4.6 & 37.1 & 36 & 3 \\
\hline 170 & 57 & 55 & 3.6 & 40.4 & 39.8 & 1.4 \\
\hline 180 & 62.7 & 60.2 & 4.1 & 44.5 & 43.5 & 2.3 \\
\hline
\end{tabular}

Table 2: Comparison of the Clarke and Wright (CW) algorithm with the Nearest Neighbour (NN) algorithm for sludge emptying $(n=10)$. 


\subsection{Sensitivity analysis}

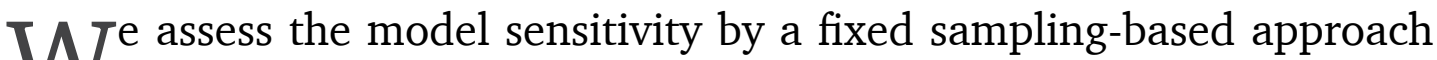
(Saltelli et al. 2004). We assess the model sensitivity by determining all model parameters resulting in possible routing changes and thus cost changes in a first step (first selection in Table 1). Parameters influencing only the absolute costs for all modelled catchments are merely of secondary interest, as they only increase or decrease costs proportionally over all OST plant densities (for example, by changing the fixed travel costs per $\mathrm{km}$ ). These parameters need to be adapted to the case study. In a second step, we select all parameters relating to residual management, as this is the most cost-intensive task (compare Figure 5). This leaves us with eleven parameters for which we define reasonable value ranges and use the extreme and base values to create a set of parameter configurations (see Table 1). From this set, we randomly select and calculate fifty parameter configurations for each emptying approach. This results in a range of different cost curves (Figure 5) representing the sensitivity of the spatial dependence of the costs.

\subsection{Case study Canton of Bern (Switzerland)}

W e apply our model to an administrative area in Switzerland (Canton of Bern) (Fig A.1). This area is located in western Switzerland and covers $\sim 6000 \mathrm{~km}^{2}$, contains 65 large ( $>1000 \mathrm{PE}$ ) wastewater treatment plants and roughly 1000 OST systems (AWA and UWE 2010). We therefore calculate an overall density of $\sim 0.19$ OST plants per $\mathrm{km}^{2}$ with locally varying densities (Fig. A.2). ${ }^{9}$ We chose this case study because this is an area where the provision of centralised wastewater services has already reached its limits today. This is confirmed by the higher OST plant density compared to the whole of Switzerland. In the case study area, each community is responsible for the operation and maintenance of OST plants and the regulatory agency is responsible for ensuring that the laws are observed. For instance, local regulations require that OST plants are emptied at least once a year (AWA 2014).

The calculation steps outlined in Section 2.3 are applied to the case study 1 area, with the city of Bern being close to the catchment's centre (Fig. A.1). We calculate truck-based transportation costs for the case study on the basis of parameters collected by the Swiss Federal Statistical Office (BFS 2009, BFS 2013, BFS 2015). For the suction truck, we assume average fuel consumption of 33 litres per $100 \mathrm{~km}$ at a diesel price of $\$ 1.34$ / litre for the year 2014 (BFS 2015b). The average speed is set at $50 \mathrm{~km}$ per hour, which corresponds to the official speed limit within settlement areas

9 Because there are significant areas covered with glaciers or without vegetation on the borders of the case study area, we subtract these for the density calculation (see Appendix A). 
and is similar to average speed assumptions in other logistics studies (inter alia Zamorano et al. 2009). The accumulation of sludge per year typically depends on the residence time in the OST plants, and we refer here to the literature for the accumulation rates (inter alia Franceys et al. 1992). We did not perform a detailed time analysis assessment (e.g. with method-time measurements) but chose a time interval for each time parameter on the basis of our own expertise. The chosen standard parameter values can be used as a starting point for further detailed analysis (cf. Table 1). We use typical transportation costs per $\mathrm{km}$ and Swiss hourly rental costs for a minivan used to perform repair and service tasks (Mobility 2015), and calculate hourly rental costs for the suction truck with the aid of cost data from a rental company for these trucks (Amphitec 2015').

\section{Results}

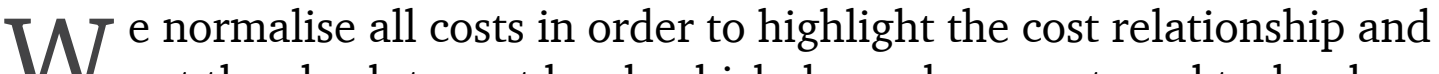
not the absolute cost level, which depends on cost- and technology assumptions specific to the case study. ${ }^{10}$

\subsection{Costs of space-sensitive tasks}

7 igure 4 shows that costs decrease exponentially with increasing plant 1 density and that emptying costs are the highest for the defined tasks. The shape of this density-cost relationship can be described as a 'hockey-stick'. As expected, scheduled emptying is more efficient than unscheduled emptying, especially for low OST plant densities. For lower densities, the scheduled and unscheduled curves approximate as more time is spent driving to the depot, making less time available for possible route optimisation by visiting multiple OST along the same route.

\subsection{Model sensitivity}

$\mathrm{F}$ igure 5 shows the average cost curve of the different input parameter sets with respective sensitivity bands. We generally find the highest model sensitivity in the range where the cost-density relationship starts to level out $\left(\sim 0.1-0.5 \mathrm{OST} / \mathrm{km}^{2}\right)$. Comparing the current average OST density for the whole case study area, we notice that we are close to the range where costs start to level out (see blue line in Figure 5), even though regional differences exist (cf. Fig. A.2).

\subsection{Routing algorithm comparison}

$T$ he calculated cost differences arising from selecting either the Clarke and 1 Wright algorithm or the Nearest Neighbour algorithm are very minor. On average, the differences between these two algorithms are less than 3\% (see Table 2).

\footnotetext{
${ }^{10}$ Results with absolute costs are given in Fig. A.3.
} 


\subsection{Distance factor $f_{d}$}

7 igure 6 shows the results of the estimation of the distance factor for the F case study area (compare Section 2.5). The street network (shown in Fig. A.2) needed for this parameter estimation tends to show slight starlike behaviour with more streets oriented towards the capital city in the centre of the catchment. Street density is also higher for central areas and those with higher population densities. Two things stand out from this parameter estimation: first we see a significant difference between the two emptying approaches and note that the straight-line distance approximation is more realistic for the case of unscheduled emptying; second, the factors are relatively constant for larger areas and we have more variation for smaller areas.

We explain the differences between the cost factors by the geography of the case study. There is a tendency for the centre of the catchment (where the depot is located) to have better straight road connections to reach its periphery. Scheduled emptying requires vehicles to travel across more single-tour segments in parallel to the catchment centre, resulting in longer distances travelled.

\section{Discussion}

\subsection{Economies of density and emptying approaches}

$T$ here exists a technological variety of different decentralised WMS 1 (cf. Tchonablous et al. 2004) such as for example MBR systems, constructed wetlands, SBR systems and many more. In this paper, we however argue that generic space-dependent expenditures arise in form of residual emptying, service and repair costs which are mainly irrespectively of the system choice (see Section 2.1 for an more comprehensive discussion). We see a highly non-linear relationship between space-dependentcosts and low OST densities, but low spatial cost dependencies at high densities. Sewer-based centralised sanitation shows diseconomies of scale for scattered settlements and has well been studied (inter alia Townend 1959, Downing 1969). We also find decreasing economic efficiency for decentralised sanitation, although this is due to economies of density. The knowledge gained about economies of density becomes indispensable in integrated cost comparisons of centralised and decentralised WMS (cf. Eggimann et al. 2015).

The numbers show clearly that the sludge disposal costs dominate the spatial cost behaviour. We define a saturation point of the economies of density as the point at which costs do not decrease by more than $5 \%$ of the minimal costs calculated on the basis of the minimum catchment radius $r_{\text {min }}$. This percentage seems plausible given the noise of the modelling 
approach. Considering the average cost calculation of all potential input parameters in Fig. 5, we find that the average economies of density diminish at a plant density of equal to or greater than $1.3 \mathrm{OST} / \mathrm{km}^{2}$ (decreasing returns to density). This saturation point will shift depending on the emptying approaches and input parameters: we see that saturation is generally reached more quickly with scheduled than unscheduled emptying.

The identification of a saturation point and the 'hockey-stick' shaped cost relationship in the economies of density are the major findings of this investigation. They indicate that costs will be exceedingly high in the initial phase of introducing OST systems in a region until the density surpasses the saturation point. The saturation point enables the "true" costs of OST systems to be estimated if they are implemented in a certain number. This could be used as an argument for centrally regulating the introduction of OST systems (at least in an early introduction phase). Economies of density may also be moderated by the number of operators competing for service contracts in a region. As a result, effective OST plant densities will be reduced by each additional company entering the market. The number of competitors will therefore increase the necessary numbers of OST plants in a given region before their costs can be considered to be constant. This could be used as an argument to limit the number of competitors in a region (or alternatively to put out a call for tenders for servicing contracts for the entire region) in order to reap economies of densities more quickly.

A further major result relates to the outlined emptying approaches to test our model for worst and best case scenarios. On the basis of Figure 4, we conclude that the choice of emptying approach is particularly cost-relevant in low plant densities. Scheduled emptying is greatly preferable to the unscheduled alternative for low-density situations, whereas the differences decrease in high-density situations. However, even though a scheduled emptying approach is more cost-efficient, setting up a scheduled emptying tour may not be realistic because of factors such as highly fluctuating filling rates (e.g. in tourist regions). We notice that despite scheduled emptying being generally more efficient, scheduled costs are higher at very low densities because of the greater distance weighting factor (cf. Section 3.4). This preliminary result helps us to identify the optimisation potential in choosing the appropriate technology and management approaches as the specific sludge production of an OST technology seems to be more relevant than maximising the robustness of the plant. ${ }^{11}$

\footnotetext{
${ }^{11}$ We would need to assume very high failure rates or a high number of service visits in order for this cost relationship to change.
} 


\subsection{Validation}

A systematic validation of our results was not possible because no exA tensive cost data with respect to different treatment plant densities were available. We would need to know the costs for different point densities to validate the saturation point. It is therefore essential to use realistic values for the model parameters specific to the particular case study (see Table 1). Information provided by a local service operator allows us to estimate the real emptying cost of sludge and scum to be around $\$ 50$ to $\$ 100$ per $\mathrm{m} 3$ (Fritzsche and Maurer 2013) and the service cost to be between $\$ 10$ and $\$ 50$ per year (Creabeton 2015). As expected (see the limitations outlined in Section 4.4), our model underestimates both values. Whereas values could be derived from the literature for most parameters (see Table 1), we had to work with reasonable ranges for the time parameters. If more detailed time parameter estimates were required, more elaborate method-time measurements (cf. Karger and Bayha 1987) could be carried out by splitting tasks into subtasks and systematically collecting and evaluating the respective required times. In terms of the chosen routing heuristics, we believe that the Nearest Neighbour algorithm is suitable for use here, as model uncertainties resulting from different routing algorithms are minor. The results obtained are very similar to those of the computationally much less efficient Clarke and Wright algorithm. We conclude from this that it is ineffective in improving the model by heuristic optimisation.

We have shown that we can deduce a robust and distinct relationship between the infrastructure layouts of OST plants and space-dependent costs despite the abstract model design. The cost-space relationship remains robust even when our parameter sets are randomly varied (cf. Section 2.7). This robustness improves the validity of our assessed 'hockey stick' shaped cost-density relationship, as this consequentially holds for many different case studies where the individual cost parameters vary depending on the context.

\subsection{Different application contexts}

Athough we do not carry out a comparative analysis across different A infrastructure domains (Hansman et al. 2006), we are convinced that, given the generality of the presented problem, our results are not of interest only for the case of waste water management. The issues highlighted in this work are generally encountered in solid-waste handling and management and many further application contexts involving similar problems of location-routing modelling (see e.g. Yang and Ogden 2007, Nagy, and Salhi 2007 or Current et al 2002 for different application areas).The analogy to further management applications is evident, as many different household devices also depend to some degree on road-based operation 
and maintenance schemes (e.g. heating systems or washing machines). The findings concerning optimal logistics and costs relating to the distribution and density of such devices or systems are therefore applicable to fields beyond on-site sanitation.

\subsection{Limitations and future research needs}

The absolute resulting cost values are subject to several limitations: first and most important the cost structure used reflected Swiss conditions and might change in other markets. Other factors that influence costs are: first, we do not consider idle capacities of collection trucks and personnel but assume a rental system. We make this simplifying assumption as full utilisation of personnel or vehicles is often hard to achieve in real world applications if trucks are acquired and personnel is hired for sludge collection only. However, idle capacities become less important in the case of increasing densities and thus larger service organisations. This means that we generally underestimate the costs for lower densities. Second, our analysis uses underlying simplifying assumptions which need to be adapted for case study applications. For example, more sophisticated scheduling schemes could be set up taking into account increasing emptying demands after weekends. Additionally, more complex tank filling rates could be implemented or more detailed analysis could be made of the differences in space-dependency with respect to different on-site technologies. Furthermore, we neglect any potential profits made by the operators. In summary, we see many possible modifications or extensions of our analysis, such as increasing the level of realism of the modelling approach or improving the cost model. However, the main conclusions about the economies of density drawn from this model exercise still hold. Many of the mentioned limitations have an influence on the level but not on the shape of the cost curve (e.g. profits). Others are considered by using best and worst case assumptions (e.g. scheduling schemes).

Finally, we want to emphasise that in practice the discussion about onsite treatment often revolves around technology, performance and public acceptability (inter alia Massoud et al. 2009, Larsen et al. 2013). An analysis focusing on cost alone is therefore incomplete. However, costs specifically related to transportation and space are essential for decentralised WMS and it is therefore important to assess them (inter alia Kennedy-i Walker et al. 2014).

\section{Conclusion}

$\mathrm{T}$ this study, we examine the spatially dependent costs of decentral1 ised WMS. The main goal was to address the lack of knowledge about the density-related cost characteristics (i.e. economies of density) of OST 
systems. Economies of density are closely linked to the operation and maintenance of OST, and in-depth knowledge concerning this specific cost aspect of O\&M is needed to obtain improved true cost comparisons of centralised and decentralised WMS. Our model-based approach allows us to calculate economies of density for non-sewer based WMS in a systematic way for the first time. The input parameters can be adapted to specific real-world applications, and the distance parameters can be estimated.

We summarise our main findings as follows:

- In sparsely populated regions, we not only find a reduced economic efficiency for centralised WMS but also for decentralised ones due to economies of density.

- Economies of density for OST plants are highly non-linear and take the form of a 'hockey stick'.

- Economies of density depend on the chosen management approach, i.e. whether optimisation of road-based transportation is feasible or not. This is especially true for residual emptying at low plant densities where high cost savings can be achieved by optimised routing through scheduled emptying.

- We argue that knowledge about economies of density is especially important in the early introduction phases of OST systems in a region. This is because very low densities are reached in the initial introduction phase of on-site technology as only a small number of systems are implemented by first-movers. At low densities, OST costs will therefore be unduly high compared to a centralised WMS. Only after a minimum number of plants have been installed will be space-dependent costs of OST plants decrease. This cost behaviour might provide a rationale for subsidising the first OST plants in a region in order to achieve attractive prices for these services.

- Based on today's number of OST plants in the Swiss case study region, potential cost savings could be realised if more plants were installed in order to reach higher densities treatment plants. We find that the saturation point for economies of density is between 1 and 1.5 OST plants per $\mathrm{km}^{2}$. The current relatively high plant density in the overall region is close to the saturation point, even though differences exist between the various sub-regions, indicating locally distinctive costs for service, repairs and residual emptying. However, a comprehensive full-cost analysis of centralised and decentralised WMS would be needed to decide on the economically 
optimal number of OST plants in a region. The knowledge presented here prepares the ground for such an integrated cost assessment.

\section{Source Code}

The model is implemented in Python 2.7 and the source code is available under https://github.com/eggimasv/EcoDen.

\section{Acknowledgement}

We thank Eberhard Morgenroth, Heiko Gebauer and João Leitão for fruitful discussions and Richard Michell and Rachel Barrett for proof-reading. Finally, we acknowledge the feedback received from anonymous reviewers.

\section{Appendix A}

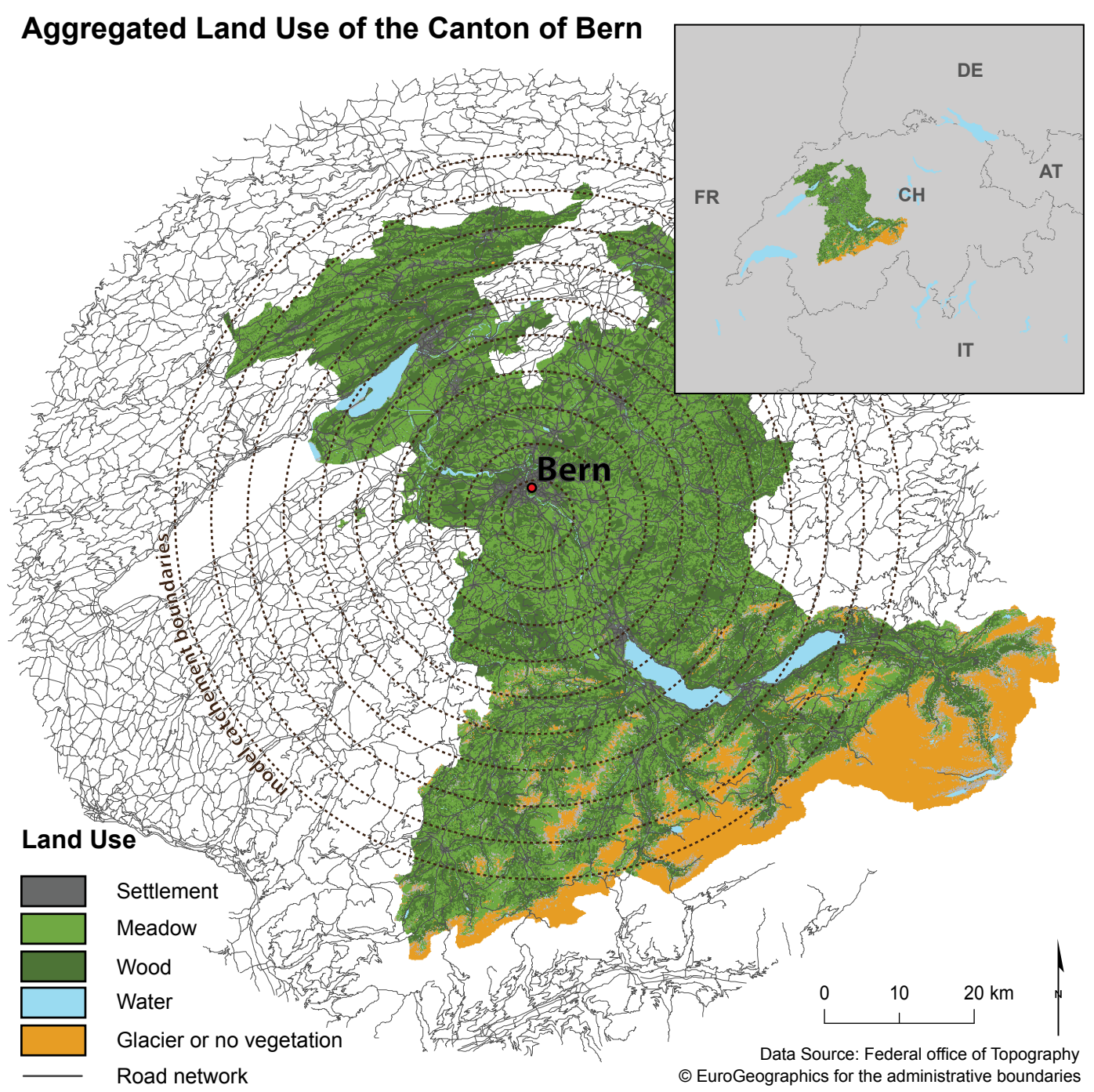

Figure A.1: Land use of the Canton of Bern. For the density calculation we do not consider land covered by vegetation or glaciers. Model catchment boundaries of the case study application up to $100 \mathrm{~km}$ are indicated with dotted circles. 


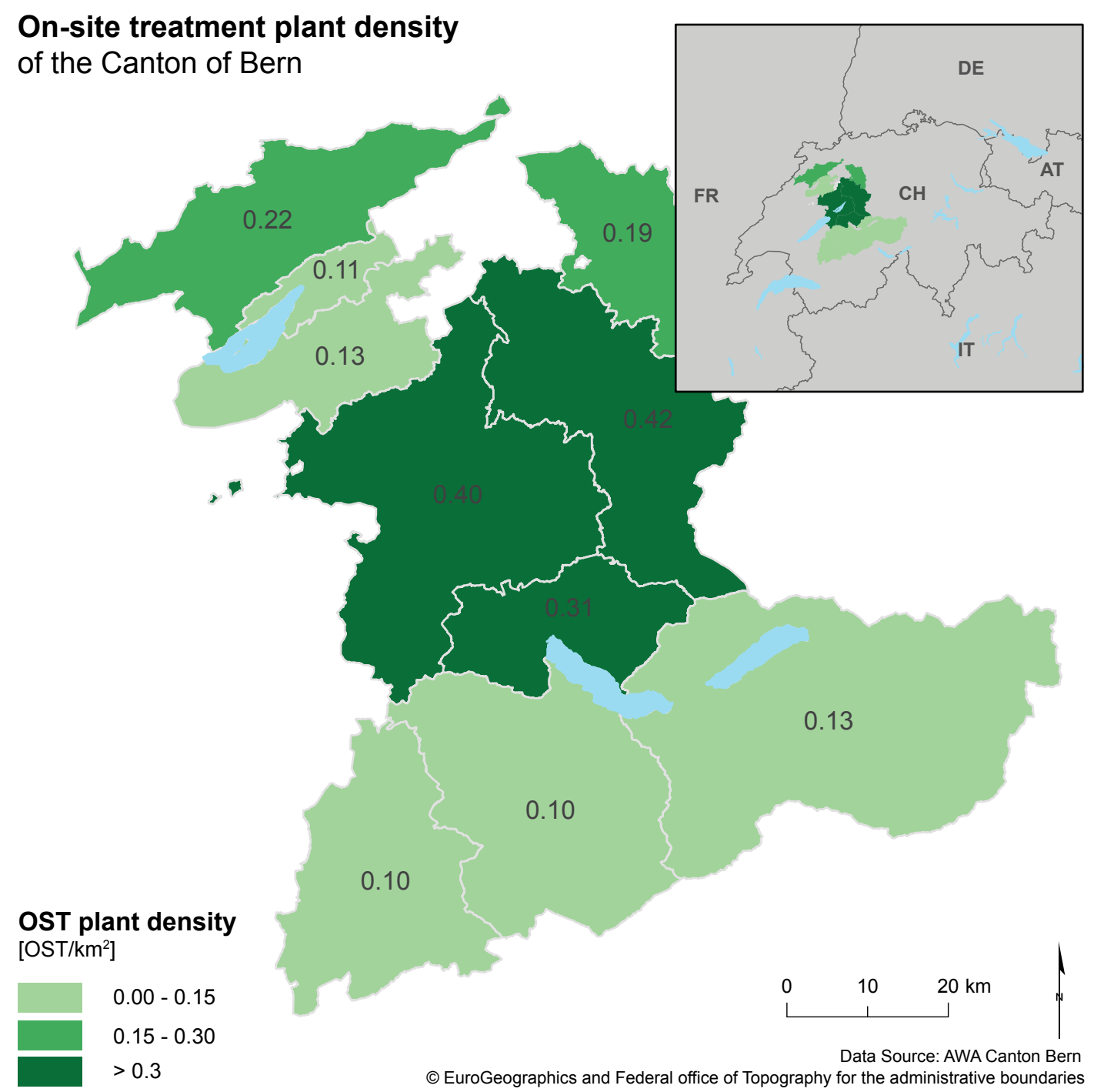

Figure A.2: Current regional OST plant density estimates within the Canton of Bern.

\section{$6 \quad$ References}

ADAMs, B. J., DAJANI, J. S., GEMmELl, R. S., 1972. On the centralization of wastewater treatment facilities. Water resources bulletin 8(4), 669-678.

Álvarez, I. C., PRIETo, Á. M., Zofío, J. L., 2014. Cost efficiency, urban patterns and population density when providing public infrastructure: a stochastic frontier approach. European Planning Studies, 22(6), 1235-1258.

AмPHITEC, 2015. Rental Brochure (Rental Broschüre). Link: Accessed: 30.05.2015. Archived by WebCite ${ }^{\circledR}$ http://www. webcitation.org/6YuYVDPm4 (in German).

Arnott, R., 1979. Optimal City Size in a Spatial Economy. Journal of urban economics 6, 65-89.
AWA, UWE, 2010. Sachplan Siedlungsentwässerung 2010 der Kantone Bern und Solothurn (Sectoral Plan Urban Drainage Systems 2010 of the Canton Bern and Solothurn). Switzerland. (in German).

$A W A, 2014$. Entsorgung von Rückständen aus dezentralen Abwasseranlagen (Disposal of residues of decentralised wastewater treatment plants). Koordination Nordwetschweiz, Bern, Switzerland (in German).

BAKIR, H. A., 2001. Sustainable wastewater management for small communities in the Middle East and North Africa. Journal of environmental management, 61, 319-328.

BARNES, G., LANGWORTHY, P., 2003. The per mile costs of operating automobiles and trucks. Final Report. Minnesota Department of Transportation, MN, USA. 

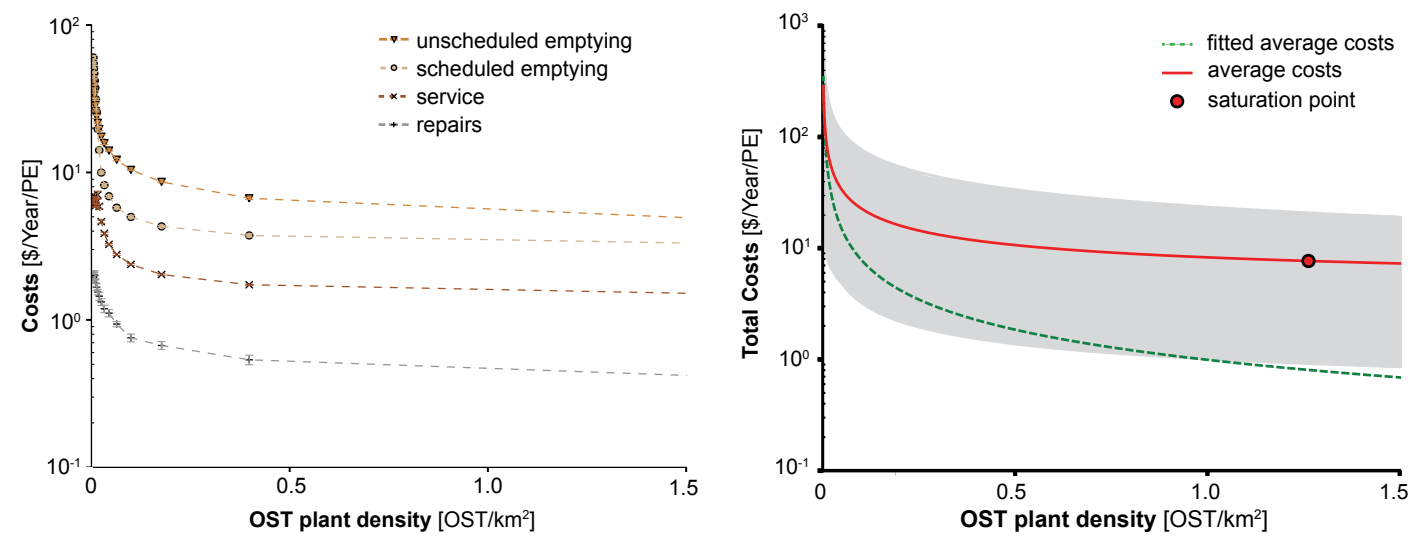

c.)

d.)
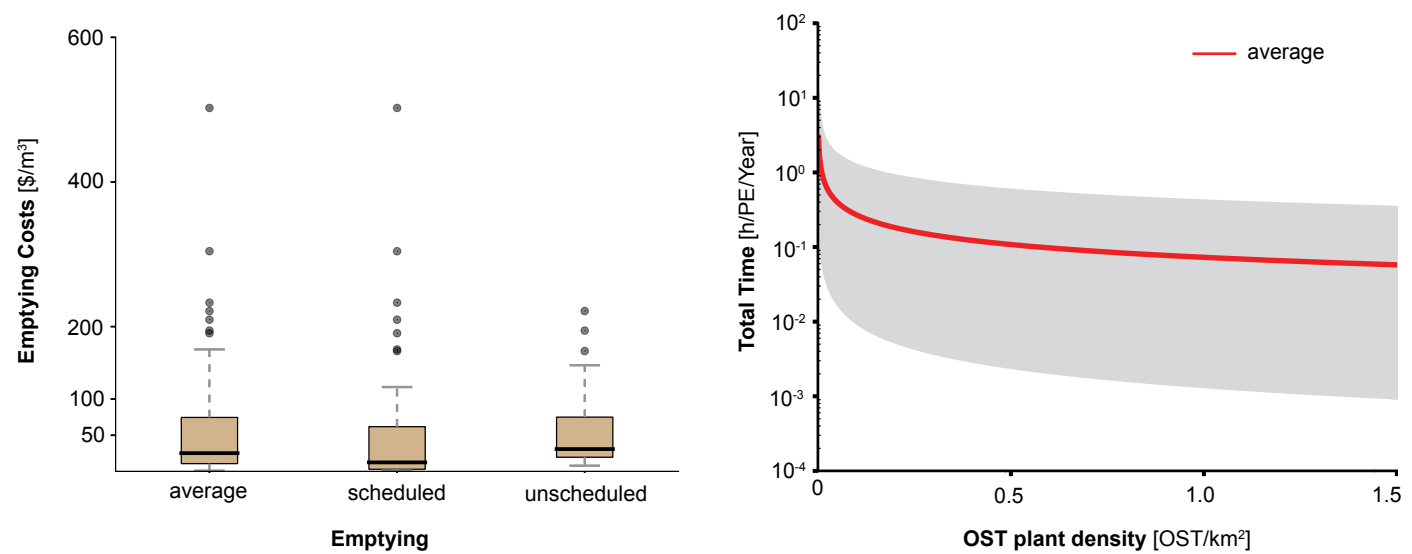

Fig A.3: Non-normalised costs for Figure 4 (a), Figure 5 (b), non-normalised total emptying costs (c) and total time results $(d)(n=100)$.

BFS, 2009. Transportrechnung - Jahr 2005 (Transport Accounting - Year 2005). Neuchâtel, Switzerland (in German).

$B F S$, 2013. Betriebsübliche Arbeitszeit nach Wirtschaftsabteilungen (Typical working times for different economic devisions). Neuchâtel, Switzerland (in German).

BFS, 2015 . Schweizerische Lohnstrukturerhebung 2012 (Swiss Earnings Structure Survey 2012). Neuchâtel, Switzerland (in German).

BFS, 2015b. Treibstoff - Durchschnittspreise pro Liter in Franken (Fuel - Average prices per litre in Francs), Neuchâtel, Switzerland, (in German).

BRADLEY, B., DAIGGER, G., RUBIN, R., TCHOBANoglous, G., 2002. Evaluation of onsite wastewater treatment technologies using sustainable development criteria. Clean Technologies and Environmental Policy 4, 87-99.

BUCHANAN, J. R., 2014. Decentralized Wastewater Treatment. Book chapter, volume three, 'Remediation of Polluted Water', in the Series 'Comprehensive Water Quality and Purification.' Elsevier, Oxford, UK.

CAMBRIDGE Systematics, 1995. Characteristics and Changes in Freight Transportation Demand: A Guidebook for Planners and Policy Analysts. Appendix F. Prepared for NCHRP Project 8-30. Washington, USA.

Christaller, W., 1933. Die zentralen Orte in Süddeutschland. Reprinted in: Wissenschaftliche Buchgesellschaft (eds.), 1980, Third Edition, Darmstadt, Germany.

Clarke, G., Wright, J. W., 1964. Scheduling of vehicles from a central depot to a number of delivery points. Operations Research, $12,568-581$.

Cormen, T. H., Leiserson, C. E., Rivest, R. L., Stein, C., 2009. Introduction to Algorithms. MIT Press, Cambridge, Massachusetts, London, UK.

CREABETON, 2015. Mechanisch-biologische Kleinkläranlagen (Mechanical and 
biological small-scale wastewater treatment plants). Einingen, Switerland. Link: Accessed: 30.06.2015. Archived by WebCite ${ }^{\circledR}$ http://www.webcitation. org/6ZfjCunUO

CRites, R., TChobanoglous, G., 1998. Small and decentralized wastewater management systems. WCB McGraw-Hill, Boston, USA.

Current, J., Daskin, M.D., Schilling, 2002, "Discrete Network Location Models," Chapter 3 in facility location theory: applications and methods , Z. Drezner and H. Hamacher (eds.), Springer-Verlag, Berlin, 81-118.

DiJKSTRA, E. W., 1959. A note on two problems in connexion with graphs. Numerische Mathematik 1, 269-271.

DodANe, P.-H., MBÉGUÉRÉ, M., SOW, O., STRANDE, L., 2012. Capital and Operating Costs of Full-Scale Faecal Sludge Management and Wastewater Treatment Systems in Dakar, Senegal. Environmental Science and Technology, 46, 3705-3711.

Downing, P. B., 1969. The economics of urban sewage disposal. Praeger, New York, NY, USA.

EgGiMANN, S., TRUfFER, B., MAURER, M., 2015. To connect or not to connect? Modelling the optimal degree of centralisation for wastewater infrastructures. Water Research, 84, 218-231.

EPRI, 2000. Advanced On-Site Wastewater Treatment and Management Market Study. Volume 2: State Reports, Palo Alto, CA, USA.

EtNier, C., Nelson, V., Pinkham, R., 2000: Economics of Decentralized Wastewater Treatment Systems: Direct and Indirect Costs and Benefits. A white paper for the National Decentralized Water Resources Capacity Development Project. In: National Research Needs Conference Proceedings: Risk-Based Decision Making for Onsite Wastewater Treatment, St. Louis, MO, USA.

FINKELSTEIN, M., 2008. Failure Rate Modelling for Reliability and Risk. Springer Series in Reliability Engineering, London, UK.

FLETCHER, H., MACKLEY, T., JUDD, S., 2007. The cost of a package plant membrane bioreactor. Water Research, 41, 2627-35.

Flotats, X., Bonmatí, A., Fernández, B., MAGRÍ, A., 2009. Manure treatment technologies: on-farm versus centralized strategies. NE Spain as case study. Bioresource Technology, 100, 5519-26.
FRANCEYS, R., PICKFORD, J., REED, R., 1992. A Guide to the Development of on-Site Sanitation. WHO.

Friedler, E., Pisanty, E., 2006. Effects of design flow and treatment level on construction and operation costs of municipal wastewater treatment plants and their implications on policy making. Water Research, 40, 3751-3758.

FRITZSCHE, C., MAURER, M., 2013. Selected Prices and Costs for Swiss Urban Water Infrastructure. Eawag, Dübendorf, Switzerland.

GENDREAU, M., LAPORTE, G., SÉGUIN, R., 1996. Stochastic vehicle routing. European Journal of Operational Research, 88, 3-12.

GHOSE, M.K., DiKSHIT, A.K., SHARMA, S.K., 2006. A GIS based transportation model for solid waste disposal - A case study on Asansol municipality. Waste Management, 26(11), 1287-1293.

GonzÁLez-Gómez, F., García-Rubio, M. A., 2008. Efficiency in the management of urban water services. What have we learned after four decades of research? Hacienda Pública Española, 185, 39-67.

Guerrini, A., Romano, G., Campedelli, B., 2013. Economies of Scale, Scope, and Density in the Italian Water Sector: A Two-Stage Data Envelopment Analysis Approach. Water Resources Management, 27, 4559-4578.

Guo, T., EnglehardT, J., 2015. Principles for scaling of distributed direct potable water reuse systems: A modeling study. Water Research, 75, 146-163.

Hamilton, B. A., Pinkham, R. D., Hurley, E., Watkins, K., Lovins, A. B., Magliaro, J., ETNIER, C., NELSON, V., 2004. Valuing Decentralized Wastewater Technologies: a catalog of benefits costs and economic analysis techniques. Rocky Mountain Institute, Snowmass, USA.

Hansman, R. J., Magee, C., Neufville, R. DE., Robins, R., Roos, D., 2006. Research agenda for an integrated approach to infrastructure planning, design and management. International journal of critical infrastructures, 2(2/3), 146-159.

HaUG, P., 2004. Decreasing population and rising costs of providing water and sewage treatment for urban areas: a case study, Halle (Saale), Germany.

Hendrickson, T. P., NGUyen, M., SukARdi, M., Miot, A., Horvath, A., Nelson, K. L. 
2015. Life-cycle energy use and greenhouse gas emissions of a building-scale wastewater treatment and non-potable reuse system. Environmental Science and Technology, 49, 10303-10311.

Holmes, T. J., 2011. The diffusion of wal-mart and economies of density. Econometrica, 79(1), 253-302.

Hug, T., Maurer, M., 2012. Stochastic modeling to identify requirements for centralized monitoring of distributed wastewater treatment. Water Science and Technology, 65(6), 1067-1075.

Johnson, D. S., Papadimitriou, C. H., 1985. Performance guarantees for heuristics. In: Lawler, E. L., Lenstra, J. K., Rinnooy Kan, A. H. G., Shmoys, D. B. (eds.),1985. The Traveling Salesman Problem. A Guided Tour of Combinatorial Optimization. Wiley, Chichester, UK.

KAMINSKY, J., JAVERNICK-WILL, A., 2013. Contested Factors for Sustainability: Construction and Management of Household On-Site Wastewater Treatment Systems. Journal of Construction Engineering \& Management, 139(12), A4013004.

KARGER, D. W., BAYHA, F. H., 1987. Engineered Work Measurement. Fourth Edition, Industrial Press, NY, USA.

KENNEDY-WALKER, R., HOLDERNESS, T., BARR, S., ALDERSON, D., EVANS, B., 2014. Network modelling for road-based faecal sludge management. Proceedings of the ICE Municipal Engineer, 167(3), 157-165.

LARSEN, T. A., UDERT, K. M., LIENERT, J., 2013. Source Separation and Decentralization for Wastewater Management. IWA Publishing, London, UK.

LAWLER, E. L., LENSTRA, J. K., RiNNOOY KAN, A. H. G., ShMors, D. B. (EDS.), 1985. The Traveling Salesman Problem. A Guided Tour of Combinatorial Optimization. Wiley, Chichester, UK.

LeE, E. J., CRiddLe, C. S., Bobel, P., FreyberG, D. L., 2013. Assessing the scale of resource recovery for centralized and satellite wastewater treatment. Environmental Science and Technology, 47, 10762-10770.

Libralato, G., Ghirardini A. V., Avezż̀, F., 2012. To centralise or to decentralise: An overview of the most recent trends in wastewater treatment management. Journal of Environmental Management, 94, 61-68.
MARKARD, J., 2009. Characteristics of Infrastructure Sectors and Implications for Innovation Processes. Discussion Paper for the Workshop on Environmental Innovation in Infrastructure Sectors, Karlsruhe Sept. 29-Oct. 1, Germany.

MARUFUZZAMAN, M., EKŞIOĞLU, S. D., HERNANDEZ, $R ., 2015$. Truck versus pipeline transportation cost analysis of wastewater sludge. Transportation Research Part A: Policy and Practice, 74, 14-30.

Massoud, M. A., TARHINI, A., NASR, J. A., 2009. Decentralized approaches to wastewater treatment and management: applicability in developing countries. Journal of Environmental Management, 90, 652-9.

MAURER, M., RothenBERGER, D., LARSEN, T. A., 2006. Decentralised wastewater treatment technologies from a national perspective: at what cost are they competitive? Water Science and Technology, 5(6), 145-154.

MaURer, M., Wolfram, M., Herlyn, A., 2010. Factors affecting economies of scale in combined sewer systems. Water Science and Technology, 62(1), 36-41.

Michaelewicz, Z., FogeL, D. B., 2004. How to Solve It: Modern Heuristics. 2nd revised and extended edition, Springer, Berlin, Germany.

MikHael, G., RobiIns, D. M., Ramsay, J. E., MBÉGUÉRÉ, M., 2014: Methods and Means for Collection and Transport of Faecal Sludge. In: Strande, L., Ronteltap, M., Brdjanovic, D. (eds.), Faecal Sludge Management Systems Approach for Implementation and Operation, IWA Publishing.

MoвILITY, 2015. Overview of mobility rates. Link: Accessed: 30.05.2015. Archived by WebCite ${ }^{\circledR}$ http://www.webcitation. org/6YuZ3WJAv

NAGY, G., SALHI, S., 2007. Location-routing: Issues, models and methods. European Journal of Operational Research, 177(2), 649-672.

OECD, 2015. Water and Cities: Ensuring Sustainable Futures, OECD Studies on Water, OECD Publishing, Paris, France.

PARKINSON, J., TAYLER, K., 2003, Decentralized wastewater management in peri-urban areas in low-income countries. Environment \& urbanization, 15(1), 75-90.

Poustie, M. S., Deletic, A., Brown, R. R., WONG, T., DE HAAN, J., SKINNER, R., 2014. Sustainable urban water futures in 
developing countries: the centralised, decentralised or hybrid dilemma. Urban Water Journal, 1-16.

Saltelli, A., Tarantola, S., Campolongo, F., RATTO, M., 2004. Sensitivity analysis in practice. A guide to assessing scientific models. Wiley \& Sons, Chichester, UK.

SCHILLER, G., SIEDENTOP, S., 2005. Follow-up costs for infrastructure of settlement development in the case of decrease in population (Infrastrukturfolgekosten der Siedlungsentwicklung unter Schrumpfungs-bedingungen). DISP The Planning Review, 41(160), 83-93 (in German).

SEMIYAGA, S., OKURE, M. A. E., NIWAGaBA, C. B., Katukiza, A. Y., KansiIme, F., 2015. Decentralized options for faecal sludge management in urban slum areas of Sub-Saharan Africa: A review of technologies, practices and end-uses. Resources, Conservation and Recycling, 104, 109-119.

Singh, N. K., Kazmi, A. A., StaRkL, M., 2015. A review on full-scale decentralized wastewater treatment systems: techno-economical approach. Water Science \& Technology, 71, 468-478.

Starkl, M., Parkinson, J., Narayana, D., FLAMAND, P., 2012. Small is beautiful but is large more economical? Fresh views on decentralised versus centralised wastewater management. Water21(June), 45-47.

Steiner, M., Agnès, M., KonÉ, D., Strauss, M., 2002. Economic Aspects of Low-cost Faecal Sludge Management. Eawag, Dübendorf, Switzerland.

TAVARES, G., Zsigraiova, Z., SEMIAO, V., CaRvalHo, M.G., 2009. Optimisation of MSW collection routes for minimum fuel consumption using 3D GIS modelling. Waste Management, 29(3), 1176-85.

TCHOBANoglous, G., RupPe, L., LEVERENZ, H., DARBY, J., 2004. Decentralized wastewater management: challenges and opportunities for the twenty-first century. Water Science and Technology: Water Supply, 4(1), 95-102.

TCHOBANoglous, G., LEVERENZ, H., 2013. The rationale for decentralization of wastewater infrastructure. In: T. A., Udert, K. M., Lienert, J. (eds.), Source Separation and Decentralization for Wastewater Management, Larsen, IWA Publishing, London, UK.
TownEND, C. B., 1959. The economics of the disposal of sewage and trade effluents. Bull. World Health Organ. 20, 535-562.

Truffer, B., Binz, C., Gebauer, H., STÖrmer, E., 2013. Market success of on-site treatment: a systemic innovation problem. In: Larsen, T. A., Udert, K. M., Lienert, J. (eds.), Source Separation and Decentralization for Wastewater Management, IWA Publishing, London, UK.

VON THÜNEN, J. H. V., 1875. Der isolierte Staat in Beziehung auf Landwirtschaft und Nationalökonomie. Reprinted in: Wissenschaftliche Buchgesellschaft (eds.), 1966, Third Edition, Darmstadt, Germany.

WEGENER, M., 2011: Transport in spatial models of economic development. In: Palma, A. D., Lindsey, R., Quinet, E., Vickerman, R., (eds.) 2011: A handbook of transport economics. Edward Elgar Publishing, Cheltenham, UK.

WENBAN-SMITH, H. B., 2009. Economies of scale, distribution costs and density effects in urban water supply: a spatial analysis of the role of infrastructure in urban agglomeration. PhD thesis, The London School of Economics and Political Science (LSE), UK.

WERF, 2015. Performance and cost of decentralized unit processes. Link: http:// www.werf.org

WORLD BANK, 2014. PPP conversion factor. International Comparison Program database. Available at: http://data.worldbank.org/

YANG, C., OGDEN, J., 2007. Determining the lowest-cost hydrogen delivery mode. International Journal of Hydrogen Energy, 32(2), 268-286.

Zamorano, M., Molero, E., Grindlay, A., Rodríguez, M. L., HuRtado, A., Calvo, F. $J ., 2009$. A planning scenario for the application of geographical information systems in municipal waste collection: A case of Churriana de la Vega (Granada, Spain). Resources, Conservation and Recycling, 54, 123-133.

ZEPPINI, P., FRENKEN, K., KUPERS, R., 2014. Thresholds models of technological transitions. Environmental Innovation and Societal Transitions, 11, 54-70. 